\title{
EFEITO DE DIFERENTES TEMPERATURAS NA GERMINAÇÃO E CRESCIMENTO RADICULAR DE SEMENTES DE JATOBÁ-MIRIM (Guibourtia hymenaefolia (Moric.) J. Léonard)
}

\author{
TEMPERATURE EFFECT ON THE GERMINATION AND ROOT GROWTH OF JATOBÁ-MIRIM \\ (Guibourtia hymenaefolia (Moric.) J. Léonard) SEEDS
}

\author{
Ademir Kleber Morbeck de Oliveira ${ }^{1}$ Kelly Cristina Lacerda Pereira ${ }^{2}$
}

\begin{abstract}
RESUMO
A espécie Jatobá-Mirim pertence à família Fabaceae, apresentando-se distribuída pelos biomas Pantanal e Caatinga. Sua madeira é indicada para construção civil e confecção de mobiliário de luxo, e a árvore é recomendada para arborização urbana e utilizada para a composição de reflorestamentos heterogêneos. Levando-se em consideração seu potencial de utilização, este trabalho foi desenvolvido com o objetivo de verificar o efeito de diferentes temperaturas sobre as taxas de germinação e crescimento radicular inicial de sementes de Jatobá-Mirim. As sementes utilizadas no experimento foram coletadas na Fazenda Cabeceira do Prata, Município de Jardim, Mato Grosso do Sul, em setembro de 2009. O material coletado foi transportado para o Laboratório de Pesquisa em Sistemas Ambientais e Biodiversidade da Universidade AnhangueraUniderp, no qual o experimento foi desenvolvido. As sementes foram submetidas a seis tratamentos, em temperaturas constantes, de $20,25,30$ e $35^{\circ} \mathrm{C}$ e alternadas de $20-30$ e $25-35^{\circ} \mathrm{C}$ em câmaras de germinação tipo BOD. Os resultados obtidos evidenciaram maior percentagem de germinação das sementes nas temperaturas de $30^{\circ} \mathrm{C}(90 \%), 35^{\circ} \mathrm{C}(97 \%)$ e $25-35^{\circ} \mathrm{C}(90 \%)$, estatisticamente iguais, indicando que estas temperaturas são mais eficazes em promover a germinação. Levando-se em consideração o tempo médio de germinação, índice de velocidade de germinação e produção de matéria seca, as temperaturas constantes de 30 e $35^{\circ} \mathrm{C}$ se destacam, sendo seus resultados estatisticamente iguais e superiores aos demais tratamentos.
\end{abstract}

Palavras-chave: matas calcárias; sementes florestais; espécies nativas.

\begin{abstract}
Jatobá-Mirim species belongs to Fabaceae family and is distributed through Pantanal and Caatinga areas. Its wood is suitable for the construction and the manufacture of luxury furniture and is recommended for urban forestry and used to compose heterogeneous reforestation. Taking into account their potential use this work was developed with the objective of evaluating the effect of different temperatures on the germination rate and initial root growth of Jatobá-Mirim seeds. The seeds used in this experiment were harvested at 'Cabeceira do Prata' farm, located in 'Jardim' municipality, in Mato Grosso do Sul state, in September 2009. The material collected was transported to the Laboratory of Research on Bio-diversity and Environmental Systems at Anhanguera-Uniderp University where the research was developed. The seeds were submitted to constant temperatures of $20,25,30,35{ }^{\circ} \mathrm{C}$ and alternated temperatures of 20 30 and $25-35^{\circ} \mathrm{C}$, in six treatments, kept in germination cameras of B.O.D type. The obtained results show that the best temperatures for the seed germination are $30{ }^{\circ} \mathrm{C}(90 \%), 35^{\circ} \mathrm{C}(97 \%)$ and $25-35{ }^{\circ} \mathrm{C}(90 \%)$, statistically equal, certifying that those temperatures are more efficient to promote the germination. Taking into account the mean time for germination, germination speed index and dry matter production, constant temperatures of 30 and $35^{\circ} \mathrm{C}$ are better and its results, statistically equal and higher than other treatments.
\end{abstract}

Keywords: calcareous forest; forest seeds; native species.

1 Biólogo, Dr., Professor do Programa de Pós-Graduação em Meio Ambiente e Desenvolvimento Regional, Universidade Anhanguera-Uniderp, Rua Alexandre Herculano, 1400, CEP 79037-280, Campo Grande (MS), Brasil. akmorbekoliveira@gmail.com

2 Acadêmico do Curso de Ciências Biológicas, Universidade Anhanguera-Uniderp, Rua Alexandre Herculano, 1400, CEP 79037-280, Campo Grande (MS), Brasil.kellykams@hotmail.com

Recebido para publicação em 29/09/2010 e aceito em 13/11/2012 


\section{INTRODUÇÃO}

A germinação da semente é considerada como a retomada das atividades metabólicas do eixo embrionário, consequentemente culminando na emissão da raiz primária, sendo uma fase crítica, pois além de estar associada aos processos fisiológicos da semente, depende de fatores ambientais (FERREIRA e BORGHETTI, 2004), envolvendo água, luz, temperatura e oxigênio (BEWLEY e BLACK, 1994; CARVALHO e NAKAGAWA, 2000; BRASIL, 2009). A temperatura afeta significativamente o processo germinativo, influenciando principalmente na absorção de água pela semente e em todas as reações bioquímicas e processos fisiológicos que determinam a germinação (POPINIGIS, 1985; CARVALHO e NAKAGAWA, 2000). Porém, não há uma temperatura ótima e uniforme para todas as espécies (BEWLEY e BLACK, 1994).

A germinação ocorrerá dentro de determinados limites de temperatura e acima ou abaixo desses limites, ela não acontece. A temperatura ideal é aquela em que ocorre o máximo de germinação no menor espaço de tempo (CARVALHO e NAKAGAWA, 2000; MARCOS FILHO, 2005).

A temperatura também é fundamental para o desenvolvimento das estruturas iniciais da plântula, tais como a raiz primária, a qual, durante a germinação, geralmente, é a primeira estrutura a salientar-se, tendo ela um papel crucial no processo de estabelecimento da plântula no ambiente; temperaturas inadequadas afetam diretamente esta estrutura, que está em rápido processo de divisão celular e qualquer fator ambiental adverso pode levar a uma diminuição da capacidade de desenvolvimento (LARCHER, 2003).

Entre as espécies do Pantanal com interesse econômico e poucas informações sobre seus processos germinativos encontra-se Guibourtia $w$ ((Moric.) J. Leonard), pertencente à família Fabaceae, e conhecida popularmente como JatobáMirim. É uma planta semidecídua, com altura variando de 10 a 18 metros, sendo característica e exclusiva de matas secas e calcárias do Pantanal e na caatinga arbórea do Nordeste. Sua madeira, muito pesada e de boa resistência mecânica, é indicada para construção civil, confecção de mobiliário de luxo e a árvore, além de ter atributos ornamentais e ser recomendada para arborização urbana, é utilizada para a composição de reflorestamentos heterogêneos com fins preservacionistas (LORENZI, 2009).
Em decorrência da carência de estudos sobre germinação para a flora brasileira, principalmente tratando-se do conhecimento da biologia e ecologia de plantas nativas, objetivou-se com este trabalho, verificar o efeito de diferentes temperaturas na germinação e crescimento inicial de sementes de Jatobá-Mirim.

\section{MATERIAL E MÉTODOS}

Os frutos e sementes foram recolhidas diretamente do solo, de aproximadamente sete árvores matrizes, em área de mata ciliar do rio da Prata, localizado na Fazenda Cabeceira do Prata (coordenadas S 21²7'54,896" W 056 26'27,501"), no município de Jardim, Mato Grosso do Sul, em setembro de 2009, com a região de coleta fazendo parte da chamada Serra de Bodoquena, borda leste do Pantanal. Após a coleta, o material foi acondicionado em sacos de polietileno e transportado para o Laboratório de Pesquisa em Sistemas Ambientais e Biodiversidade da Universidade AnhangueraUniderp, Campo Grande-MS, onde foram conduzidos os experimentos.

Em laboratório, após contagem e triagem das sementes, eliminando-se sementes atacadas por insetos, foi realizado o teste de umidade para determinar o percentual de água das sementes, seguindo o método de estufa a $105^{\circ} \mathrm{C}$ (BRASIL, 2009).

As sementes selecionadas para o teste de germinação, devido à coleta ter sido realizada no solo, foram desinfectadas superficialmente, mediante a imersão em hipoclorito de sódio (5\%) por três minutos, sendo em seguida lavadas por um minuto em água corrente. Para a avaliação do efeito da temperatura sobre a germinação, utilizou-se um total de 480 sementes nas temperaturas constantes de $20,25,30$ e $35^{\circ} \mathrm{C}$ e alternadas de $20-30$ e $25-35^{\circ} \mathrm{C}$, com quatro repetições de 20 sementes por tratamento e fotoperíodo de 12 horas em câmaras de germinação do tipo BOD - Biological Oxygen Demand. Os testes foram conduzidos em caixas transparentes $(11 \times 11 \times 3,5 \mathrm{~cm})$ sobre duas folhas de papel germitest previamente umedecidos com o fungicida Rovral ${ }^{\circledR}$ a $0,1 \%$.

A avaliação da germinação foi diária, com término no $19^{\circ}$ dia, sendo consideradas germinadas as sementes que apresentaram emissão de raiz primária, com, no mínimo, $2 \mathrm{~mm}$ de comprimento. Foi avaliada a percentagem de germinação $(\% \mathrm{G})$, o índice de velocidade de germinação (IVG) e o tempo médio de germinação (TMG). A percenta- 
gem de germinação foi transformada em arco-seno $(\mathrm{x} / 100)^{0,5}$ e o IVG, para raiz quadrada do valor do $\mathrm{IVG}+0,5$. Os dados foram analisados em delineamento inteiramente casualizado e quando houve significância, foi realizado o teste de média de Tukey, em nível de $5 \%(\mathrm{p}<0,05)$. Nas sementes não germinadas, realizou-se o teste de viabilidade de tetrazólio (sal trifenil-cloreto de tetrazólio a $1 \%$ em solução aquosa) (BRASIL, 2009).

Como não foi possível avaliar a parte aérea das plântulas, devido ao período de tempo necessário para sua formação (mais de 16 dias após a germinação) e a inadequação do substrato para crescimento por um período prolongado de tempo, resultando no aparecimento inicial de sintomas de necrose nas raízes, foram consideradas plântulas as sementes que originaram raízes primárias normais (BRASIL, 2009).

Para determinar o comprimento destas, foram utilizadas todas as raízes primárias das plântulas provenientes do teste de germinação, mensurados com auxilio de régua milimétrica, sendo o resultado apresentado como média do comprimento. A massa seca (MS) foi obtida utilizando-se as raízes provenientes da medição do comprimento, acondicionadas em saco de papel do tipo kraft devidamente identificados e levados para estufa de ventilação forçada à temperatura de $80^{\circ} \mathrm{C}$ por 24 horas. Posteriormente, as raízes foram pesadas, uma a uma, em balança analítica, sendo expresso o resultado em gramas (média).

\section{RESULTADOS E DISCUSSÃO}

As sementes de Jatobá-Mirim apresentaram $7,6 \%$ de umidade, dentro da percentagem encontrada na maior parte das espécies vegetais, entre 5 e $20 \%$ (BEWLEY e BLACK, 1994).

O início do processo germinativo começou no quarto dia, nas temperaturas constantes de 30 e $35^{\circ} \mathrm{C}$ e na alternada de $25-35^{\circ} \mathrm{C}$, no quinto dia em $25^{\circ} \mathrm{C}$, no sétimo dia em $20-30^{\circ} \mathrm{C}$ e no décimo dia, em $20^{\circ} \mathrm{C}$ (Figura 1).

Parte das sementes não germinadas, nas temperaturas de 20,25 e $20-30^{\circ} \mathrm{C}$, de acordo com o teste de tetrazólio, ainda apresentavam viabilidade. A menor temperatura provavelmente diminui a velocidade dos processos metabólicos, atrasando o processo de germinação. De acordo com Baskin e Baskin (2001), temperaturas inferiores ou superiores à ótima tendem a reduzir a velocidade do processo germinativo, expondo as plântulas por maior período a fatores adversos, o que pode levar à redução no total de germinação. Já as sementes não germinadas, nas temperaturas de 30,35 e $25-35^{\circ} \mathrm{C}$, não estavam mais viáveis.

De acordo com Lorenzi (2009), a emergência em canteiros ocorre em 4-5 semanas, indicando que em condições de laboratório, em BOD, o início do processo de germinação é mais rápido. Porém, Carvalho e Nakagawa (2000) colocam que os processos de germinação são diferentes e as espécies apresentam variações em suas estratégias germinativas na dependência do local de coleta e os resultados obtidos podem variar na dependência da técnica de coleta, tempo de armazenamento e infestação por patógenos das sementes.

As temperaturas mais elevadas, constantes $\left(30\right.$ e $\left.35^{\circ} \mathrm{C}\right)$ e alternada $\left(25-35^{\circ} \mathrm{C}\right)$, apresentaram as melhores médias acumuladas (Figura 1), indicando que, possivelmente, ocorreu aumento da atividade enzimática e/ou maior difusão de gases, em resposta ao aumento da temperatura, favorecendo o processo germinativo e levando a uma maior germinação.

As temperaturas mais baixas, constantes $\left(20\right.$ e $\left.25^{\circ} \mathrm{C}\right)$ e alternada $\left(20-30^{\circ} \mathrm{C}\right)$, obtiveram menor taxa de germinação acumulada (Figura 1), demonstrando sua inadequação para as sementes desta espécie.

O processo de germinação ocorreu em todos os tratamentos, porém, as temperaturas constantes de 30 e $35^{\circ} \mathrm{C}$ e a alternada de $25-35^{\circ} \mathrm{C}$ resultaram em maiores percentagens de germinação, estatisticamente iguais entre si e superiores aos demais tratamentos. Mas avaliando-se o IVG e TMG, as temperaturas constantes de 30 e $35^{\circ} \mathrm{C}$ possuem os resultados mais significativos, estatisticamente

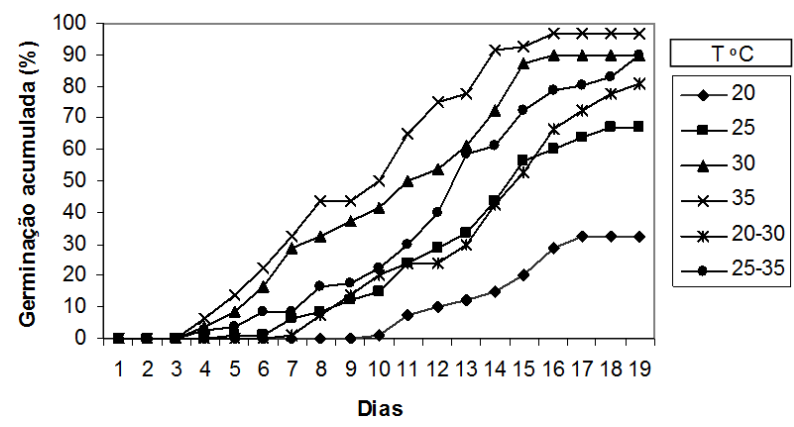

FIGURA 1: Percentagem média de germinação acumulada de sementes Jatobá-Mirim em seis temperaturas.

FIGURE 1: Accumulated germination average percentage of Jatobá-Mirim seeds maintained at six temperatures. 
iguais, propiciando melhor percentagem de germinação e vigor (Tabela 1). O IVG e TMG da temperatura alternada $\left(25-35^{\circ} \mathrm{C}\right)$ indicou menor vigor, com maior tempo de germinação, demonstrando que no período de tempo (12 horas) em que a semente esteve submetida à temperatura de $25^{\circ} \mathrm{C}$ ocorreu uma interferência negativa no processo de germinação da semente.

Em condições de canteiro, com substrato organoarenoso, a taxa de emergência é pequena e o desenvolvimento da planta, lento (LORENZI, 2009), demonstrando que, para a obtenção de maiores percentagens de germinação, o ideal é a utilização de BOD em temperaturas entre 30 e $35^{\circ} \mathrm{C}$. A germinação, de acordo com o método "botânico" (raiz primária com $2 \mathrm{~mm}$ de comprimento), em BOD é mais rápida; porém, para a formação completa da plântula é necessário um maior período de tempo de estudo, já que aos 16 dias de experimento não havia ocorrido a formação da parte aérea, o que é condizente com a colocação do autor citado.

De acordo com Carvalho e Nakagawa (2000), temperaturas inferiores ou superiores à ótima tendem a reduzir a velocidade do processo germinativo, expondo as plântulas por maior período de tempo a fatores adversos, o que pode levar à redução no total de germinação, no vigor e/ou no tempo médio de germinação, o que ocorreu principalmente nas temperaturas de 20 e $25^{\circ} \mathrm{C}$ e $20-30^{\circ} \mathrm{C}$, onde as temperaturas menores, mesmo por um período de $12 \mathrm{~h}$, causaram uma diminuição no vigor das sementes.

Algumas espécies apresentam germinação em diferentes temperaturas, tal como relatado por Varella et al. (1999) trabalhando com Ceiba pentandra (L.) Gaertn., na qual observaram que as sementes de Ceiba pentandra germinaram em uma ampla faixa de temperatura $\left(15\right.$ a $\left.35^{\circ} \mathrm{C}\right)$, apresentando melhores índices de germinação também a $30^{\circ} \mathrm{C}$ $(82 \%)$ e as demais temperaturas, índices inferiores a $58 \%$ de germinação. Já para sementes de Acacia polyphylla DC. (NETO et al., 2003), a temperatura de $25^{\circ} \mathrm{C}$ foi mais adequada para a germinação (51\%), enquanto que sementes de Aspidosperma tomentosum Mart. germinaram com maior vigor na temperatura de $20^{\circ} \mathrm{C}$ (OLIVEIRA et al., 2011).

Outros autores encontraram resultados semelhantes para temperaturas de $30^{\circ} \mathrm{C}$, como para Senna macranthera (Collad.) Irwin et Barn. (CASSARO-SILVA, 2001), Tabebuia serratifolia (Vahl) Nicholson (MACHADO et al., 2002), Tabebuia impetiginosa (Martius ex A. P. de Candolle) Standley e Tabebuia serratifolia Vahl Nich. (OLIVEIRA et al., 2005), em que a temperatura ótima permaneceu na faixa de 25 a $30^{\circ} \mathrm{C}$.

A energia da água aumenta em resposta a elevação da temperatura, provocando o aumento da pressão de difusão, que, concomitantemente, eleva a atividade metabólica e diminui o potencial interno (da semente), propiciando maior absorção de água; assim a hidratação ocorre mais rapidamente em temperaturas mais elevadas por se tratar de um processo físico (CASTRO et al., 2004), o que pode acelerar o processo germinativo. Portanto, supõe-se que, em temperaturas mais elevadas, a germinação de sementes pode ter sido afetada positivamente no desenvolvimento do embrião, apesar de altas temperaturas também poderem restringir a germinação por possíveis alterações enzimáticas, como relatado por Popinigis (1985) e Marcos Filho (2005).

TABELA 1: Percentagem de germinação, índice de velocidade de germinação (IVG), tempo médio de germinação $(\mathrm{TMG})$, comprimento da raiz primária $(\mathrm{cm})$ e peso seco da raiz primária $(\mathrm{g}) \mathrm{em}$ sementes de Jatobá-Mirim sob seis temperaturas.

TABLE 1: Germination percentage, speed germination index (SGI), mean germination time (MGT), root length $(\mathrm{cm})$ and allocation of dry mass $(\mathrm{g})$ of Jatobá-Mirim seeds submitted to six temperatures.

\begin{tabular}{cccccc}
\hline Temperaturas $\left({ }^{\circ} \mathrm{C}\right)$ & Germinação $(\%)$ & IVG & TMG & Comprimento $(\mathrm{cm})$ & Peso seco raiz $(\mathrm{g})$ \\
\hline 20 & $32 \mathrm{~d}$ & $0,49 \mathrm{e}$ & $12,9 \mathrm{~b}$ & $1,8 \mathrm{c}$ & $0,024 \mathrm{bc}$ \\
25 & $67 \mathrm{c}$ & $1,15 \mathrm{~d}$ & $12,8 \mathrm{~b}$ & $3,8 \mathrm{~b}$ & $0,019 \mathrm{c}$ \\
30 & $90 \mathrm{a}$ & $1,94 \mathrm{ab}$ & $10,6 \mathrm{a}$ & $5,8 \mathrm{a}$ & $0,032 \mathrm{a}$ \\
35 & $97 \mathrm{a}$ & $2,35 \mathrm{a}$ & $9,7 \mathrm{a}$ & $4,4 \mathrm{ab}$ & $0,027 \mathrm{ab}$ \\
$20-30$ & $81 \mathrm{~b}$ & $1,27 \mathrm{~cd}$ & $13,6 \mathrm{~b}$ & $3,8 \mathrm{~b}$ & $0,019 \mathrm{c}$ \\
$25-35$ & $90 \mathrm{a}$ & $1,63 \mathrm{bc}$ & $12,5 \mathrm{~b}$ & $4,1 \mathrm{ab}$ & $0,023 \mathrm{bc}$ \\
\hline
\end{tabular}

Médias seguidas pela mesma letra na coluna não diferem estatisticamente entre si pelo teste de Tukey ( $p>0,05)$. 
As temperaturas mais baixas de 20 e $25^{\circ} \mathrm{C}$, ou as alternadas com parte do tempo em temperatura baixa, $20-30^{\circ} \mathrm{C}$ e $25-35^{\circ} \mathrm{C}$, podem ter causado a diminuição da velocidade das reações metabólicas, afetando os processos essenciais para o início da germinação (CARVALHO e NAKAGAWA, 2000; FERREIRA e BORGHETTI, 2004), assim, retardando a velocidade de germinação, a percentagem e também aumentando o tempo médio de germinação. Larcher (2003) descreve que a faixa ótima de temperatura para espécies de regiões tropicais está entre 20 e $35^{\circ} \mathrm{C}$, embora os limites de germinação sejam diferentes, na dependência da origem das espécies.

Em relação às temperaturas alternadas, as sementes que respondem às temperaturas alternadas apresentam mecanismos enzimáticos que funcionam em diferentes temperaturas; essa resposta provavelmente corresponde a adaptações ecológicas da espécie ao ambiente (BASKIN e BASKIN, 2001). Para as sementes de Jatobá-Mirim, as temperaturas alternadas favoreceram a germinação em $25-35^{\circ} \mathrm{C}$, porém, afetaram negativamente o TMG e TMG. Para algumas sementes de espécies tropicais, a alternância de temperatura pode proporcionar melhores condições de germinação, como constataram Silva e Aguiar (2004) com Cnidosculus phyllacanthus Pax \& K. Hoffm. e Lopes et al. (2005) trabalhando com Basella rubra L., o que não foi o caso da espécie estudada.

Em referência a formação de plântulas normais, considerando-se a presença de raiz primária (BRASIL, 2009), as temperaturas de 30, 35, 2030 e $25-35^{\circ} \mathrm{C}$ apresentaram os mesmos resultados, $70 \%$ de plântulas normais, enquanto a temperatura de $25^{\circ} \mathrm{C}, 35 \%$ e $25^{\circ} \mathrm{C}, 60 \%$, novamente indicando que as menores temperaturas afetaram negativamente o processo de germinação das sementes testadas, atrasando o processo.

Analisando-se o peso seco das raízes primárias e seu comprimento, também se verifica que as temperaturas constantes de 30 e $35^{\circ} \mathrm{C}$ produziram plântulas maiores, 5,8 e $4,4 \mathrm{~cm}$, respectivamente, estatisticamente iguais, demonstrando que o crescimento da radícula foi beneficiado. Autores como Castro et al. (2004) já haviam colocado que a elevação da temperatura leva a um aumento das atividades metabólicas, propiciando maior absorção de água e hidratação, acelerando o processo germinativo. A temperatura de $30^{\circ} \mathrm{C}$ também foi a mais adequada para o crescimento radicular inicial de Parkia pendula (Willd.) Benth. ex Walp., na qual Rosseto et al. (2009) encontraram uma média de crescimento de $4 \mathrm{~cm}$ para esta espécie. Já Oliveira et al. (2012), trabalhando com plântulas de Tabebuia ochracea (Cham.) Standl, não encontraram diferenças de crescimento inicial quando as mesmas foram mantidas em temperaturas de $20,25,30,35,20$ 30 e $25-35^{\circ} \mathrm{C}$.

O crescimento em extensão da raiz primária é geralmente viável sob uma ampla faixa de temperatura, variando no mínimo de 2 a $5^{\circ} \mathrm{C}$ para espécies lenhosas de zona temperada e temperaturas acima de $10^{\circ} \mathrm{C}$ para plantas de regiões tropicais (LARCHER, 2003). A temperatura ótima para a divisão celular é de aproximadamente $30^{\circ} \mathrm{C}$ para a maioria das espécies, portanto, próxima da temperatura ótima para o crescimento (FERREIRA e BORGHETTI, 2004).

Os maiores valores de acúmulo de biomassa seca nas raízes foram observados nas temperaturas de $30^{\circ} \mathrm{C}(0,032 \mathrm{~g})$ e $35^{\circ} \mathrm{C}(0,027 \mathrm{~g})$, com as demais temperaturas apresentando valores inferiores. Estes dados confirmam que as temperaturas de 30 e $35^{\circ} \mathrm{C}$ são mais adequadas para a germinação e desenvolvimento da espécie, produzindo plântulas mais aptas a se estabelecerem no meio em menor espaço de tempo.

\section{CONCLUSÃO}

As sementes de Jatobá-Mirim germinaram em todas as temperaturas testadas, porém, os tratamentos de 30 e $35^{\circ} \mathrm{C}$ foram as condições mais adequadas para a germinação, proporcionando maior percentagem de germinação e vigor, menor tempo médio de germinação, maior crescimento e alocação de massa seca para as raízes primárias.

\section{AGRADECIMENTOS}

Os autores agradecem à Universidade Anhanguera-Uniderp pelo financiamento do Grupo Interdisciplinar de Pesquisa (GIP) e pela bolsa de iniciação cientifica concedia (PIC) e ao CNPq pela bolsa de produtividade ao primeiro autor.

\section{REFERÊNCIAS BIBLIOGRÁFICAS}

BASKIN, C. C.; BASKIN, J. M. Seeds: ecology, biogeography, and evolution of dormancy and germination. San Diego: Academic Press, 2001. $666 \mathrm{p}$.

BEWLEY, J. D.; BLACK, M. Seeds: physiology of development and germination. $2^{\text {nd }}$ ed. New York and London: Plenum Press, 1994. 445 p. 
BRASIL. Ministério da Agricultura e Reforma Agrária. Regras para Análises de sementes. Brasília: Secretaria de Defesa Agropecuária, Mapa/ ACS, 2009. $395 \mathrm{p}$.

CARVALHO, N. M.; NAKAGAWA, J. Sementes: ciência, tecnologia e produção. 4 ed. Jaboticabal: FUNEP, 2000. 588 p.

CASSARO-SILVA, M. Efeito da temperatura na germinação de sementes de manduirana (Senna macranthera (Collad.) Irwin et Barn. Caesalpiniaceae). Revista Brasileira de Sementes, Brasília, v. 23, n. 1, p. 92-99, 2001.

CASTRO, R. D.; BRADFORD, K. J.; HILHORST, H. W. M. Embebição e reativação do metabolismo. In: FERREIRA, A. G..; BORGHETTI, F. (Orgs.). Germinação: do básico ao aplicado. Porto Alegre: Artmed, 2004. p. 149-162.

FERREIRA, A. G.; BORGHETTI, F. Germinação: do básico ao aplicado. Porto Alegre: Artmed, 2004. $323 \mathrm{p}$.

LARCHER, W. Physiological plant ecology: ecophysiology and stress physiology of functional groups. Berlin; Springer, 2003. 533 p.

LORENZI, H. Árvores brasileiras: manual de identificação e cultivo de plantas arbóreas nativas do Brasil. Nova Odessa: Plantarum, 2009. 384 p. v. 2

LOPES, J. C. et al. A. Influência de temperatura, substrato e luz na germinação de sementes de bertalha. Revista Brasileira de Sementes, Brasília, v. 27, n. 2, p. 18-24, 2005.

MACHADO, C. F. et al. Metodologia para a condução do teste de germinação em sementes de ipê-amarelo (Tabebuia serratifolia (Vahl) Nicholson). Cerne, Lavras, v. 8, n. 2, p. 17-25, 2002.

MARCOS FILHO, J. Fisiologia de sementes de plantas cultivadas. Piracicaba: FEALQ, 2005. $495 \mathrm{p}$.

NETO, J. C. A.; AGUIAR, I. B.; FERREIRA, V. M. Efeito da temperatura e da germinação de sementes de Acacia polyphylla DC. Revista Brasileira de Botânica, São Paulo, v. 26, n. 2, p. 249-256, 2003. OLIVEIRA, A. K. M. et al. Germinação de sementes de Aspidosperma tomentosum Mart. (Apocynaceae) em diferentes temperaturas. Revista Brasileira de Biociências, Porto Alegre, v. 9, n. 3, p. 392-397, 2011.

OLIVEIRA, A. K. M. et al. Temperaturas para germinação de sementes de Tabebuia ochracea (Cham.) Standl. Comunicata Scientiae, Teresina, v. 3, n. 2, p. 98-103, 2012.

OLIVEIRA, L. M. et al. Temperatura e regime de luz na germinação de sementes de Tabebuia impetiginosa (Martius ex A. P. de Candolle) Standley e T. serratifolia Vahl Nich. - Bignoniaceae). Ciência e Agrotecnologia, Lavras, v. 29, n. 3, p. 642-648, 2005.

POPINIGIS, F. Fisiologia da semente. Brasília: AGIPLAN, 1985. 289 p.

ROSSETO, J. et al. Germinação de sementes de Parkia pendula (Willd.) Benth. ex Walp. (Fabaceae) em diferentes temperaturas. Revista Árvore, Viçosa, v. 33, n. 1, p. 47-55, 2009.

SILVA, L. M. M.; AGUIAR, I. B. Efeito dos substratos e temperaturas na germinação de sementes de Cnidosculus phyllacanthus Pax \& K. Hoffm. (Faveleira). Revista Brasileira de Sementes, Brasília, v. 26, n. 1, p. 9-14, 2004.

VARELA, V. P.; FERRAZ, I. D. K.; CARNEIRO, N. B. Efeito da temperatura na germinação de sementes de sumaúma (Ceiba pentandra (L.) Gaertn. - Bombacaceae) Revista Brasileira de Sementes, Brasília, v. 21, n. 2, p. 170-174, 1999. 